\title{
Processos colaborativos mediados pelo computador e as contribuições da teo- ria da atividade
}

\author{
Daniela Karine Ramos \\ Universidade Federal de Santa Catarina \\ Campus Universitário - Caixa Postal: 476 - Trindade - \\ 88040-900 - 1 andar - Bloco B/CED - Florianópolis - SC \\ daniela.ramos@ufsc.br
}

Resumo A colaboração é uma ação social, na qual pessoas compartilham objetivos e aprendem juntas visando superar desafios e construir conhecimentos. Neste sentido, este artigo apresenta os pressupostos teóricos da Teoria da Atividade e propõe a análise e discussão do trabalho colaborativo. Neste sentido para promover a colaboração utilizamos como estratégia pedagógica a "proposta de desafios", desenvolvidos a partir da metodologia da problematização e do modelo descrito pela WebQuest. Esta atividade baseada em desafios foi aplicada em uma escola pública localizada na cidade de Florianópolis em Santa Catarina, envolvendo duas turmas de oitava série, uma matutina e outra vespertina. A partir disso, observa-se os modos de organização dos grupos e as estratégias adotadas para superar e responder aos desafios propostos. Os resultados revelam que a divisão de trabalho destaca-se como estratégia adotada pelos grupos e a Teoria da Atividade revela-se consistente para compreender os processos desencadeados durante o trabalho colaborativo.

Palavras-Chave: Colaboração; Teoria da Atividade; Tecnologias da Informação e Comunicação.

\begin{abstract}
Collaboration is a social activity in which people share objectives and learn together to overcome challenges and build knowledge. In this sense, this paper presents the theoretical principles of Theory of the Activity and proposes the analysis and discussion of collaborative work. To promote collaboration we use as a pedagogic strategy the "challenge proposal" based on the methodology for analyzing a problem and model described by WebQuest. This activity is based on challenges applied in a public school located in the city of Florianópolis, Santa Catarina, involving two eighth grade history classes, one from the morning session the other in the afternoon. From this, we observe the ways of organizing groups and the strategies adopted to overcome and respond to the challenges posed. The results show that the division of labor stands out as a strategy adopted by groups and the Theory of the Activity proves consistently to understand the processes triggered during collaborative work.
\end{abstract}

Keywords: Collaboration; Theory of the Activity; Information and Communication Technology. 


\section{Introdução}

Este artigo apresenta os pressupostos teóricos da Teoria da Atividade (TA) e propõe a análise e discussão do trabalho colaborativo. Para tanto, aborda-se a TA, seus princípios e elementos, descreve-se a pesquisa empírica realizada e analisa-se os dados com base na TA, visando ampliar a compreensão do uso de recursos tecnológicos como ferramentas de mediação e os processos colaborativos. Assim, define-se como objetivo analisar a aprendizagem colaborativa apoiada por computador no processo escolar, tendo como referencial a Teoria da Atividade.

A TA parte da construção teórica de Vygotsky, apropriando-se de conceitos como mediação e relação homem e objeto, para sugerir a inclusão de novos elementos. Esta teoria teve origem nas décadas de 20 e 30, do século XX, e tem como principais colaboradores Vygotsky, Luria e Leontiev, e como principal conceito a unidade entre a consciência humana e a atividade. Outros autores também contribuíram com o estudo desta teoria, como Yrjö Engeströn, Bonnie Nardi, Victor Kaptelinin. Além disso, outra base de referência importante é o materialismo dialético de Marx e Engels [16, $17]$.

\section{Teoria da Atividade: pressupostos teóricos}

A concepção do materialismo dialético influencia a definição de atividade proposta por Leontiev, pois esta concebe o homem como um ser ativo, capaz de intervir no seu processo histórico, e pode ser compreendida como "uma estrutura dotada de passos internos e que orienta o ser humano na sua relação com o mundo dos objetos" [12].

De outra forma, a atividade busca satisfazer necessidades e logo após a satisfação de uma surgem outras. Segundo Hurtado [12], esta atividade está ligada a dois aspectos: as ações físicas e as ações psíquicas, constituídas por objetivos, motivos, ações, operações e condições que, por sua vez, vão caracterizar a atividade.

A TA, como um paradigma interdisciplinar para o estudo das diferentes formas de desenvolvimento humano, relacionada à interação entre o individual e o social, dá importância ao contexto do objeto a ser investigado e o inclui na análise [20].

Assim, a TA pode ser definida em um sentido amplo como "uma estrutura filosófica e interdisciplinar para estudar diferentes formas de práticas humanas de processos de desenvolvimento, tanto no nível individual como no nível social" [7]. Esta teoria é formada por um "conjunto de princípios que constitui um sistema integrado de atividade" [12], que possibilita ampliar a compreensão do desenvolvimento e das práticas humanas.

Esta possibilidade de ampliação do ser humano devese à importância dada às questões sociais e culturais. Desse modo, esta teoria contribui, segundo Gomes et al [7], para "um melhor design de sistemas colaborativos, por assumir que qualquer atividade de grupo é mediada por ferramentas culturais, as atividades podem ser conceitualizadas em diferentes níveis, e o entendimento conceitual das atividades é primeiro estabelecido socialmente".

O objeto da TA é compreender a unidade entre a consciência e a atividade. De acordo com Leontiev [12], consciência e atividades estão integradas, pois as atividades são consideradas formas de relação com o mundo; assim, o homem é dirigido por motivos, ou seja, de maneira intencional.

O ser humano inserido num contexto social produz sua sobrevivência por meio de interações com o seu meio e utilização de instrumentos. Segundo Lagni [12], a produção satisfaz às necessidades e também cria novas, devido ao consumo mediatizado pela necessidade de um sujeito.

Ao mesmo tempo, a TA leva em conta as noções de intencionalidade, história, mediação, colaboração e desenvolvimento. E, ainda, leva em conta a matriz social composta pelas pessoas e artefatos (instrumentos ou signos) para compreender a consciência. A atividade não pode ser compreendida sem o entendimento dos artefatos integrados às práticas sociais [18]. Assim, a mediação revela-se um conceito fundamental nessa teoria e nos possibilita analisar os dados da nossa pesquisa.

Além do conceito de mediação, outro conceito importante é o de consciência, tendo em vista que os principais proponentes da TA são a consciência e a relação do homem com as coisas ou artefatos, bem como o papel destes artefatos no cotidiano. Para Nardi [7], na TA, os artefatos são mediadores do pensamento e do comportamento humano, o que resulta em um olhar mais humano sobre o relacionamento entre pessoas e artefatos.

As atividades, como um conjunto de ações e operações direcionadas por motivos, visando alcançar determinada meta ou objetivo, podem ser concretizadas individual ou coletivamente. Segundo Lagni [7], quando uma atividade é realizada individualmente, compõe-se por três elementos: agente (indivíduo que atua sobre o objeto da atividade), objeto (o que sofre a ação, para o 
que a ação se direciona) e ferramentas de mediação (instrumentos materiais, imateriais e o próprio relacionamento recíproco entre o agente e o objeto). As ferramentas assumem o papel de mediador e "são utilizadas no processo de transformação de um objetivo sobre o objeto em questão ou para atingir uma meta desejada" [7].

De outra forma, os elementos que compõem a TA formam uma estrutura, com as seguintes componentes correlacionáveis: motivo e finalidade, que se correlacionam como atividade, ação e operação. Estes componentes são a base do modelo de atividade proposto por Leontiev para a distinção entre atividade, ação e operação. Outra distinção feita por ele refere-se à atividade principal e à atividade geral, pois o desenvolvimento da atividade principal promove mudanças nos processos psíquicos e na personalidade, de acordo com os estágios de desenvolvimento, enquanto a atividade geral, não. Assim, nem todo processo é uma atividade. De acordo com o autor "apenas aqueles processos que, realizando as relações do homem com o mundo, satisfazem uma necessidade especial correspondente a ele (...) Por atividade, designamos os processos psicologicamente caracterizados por aquilo a que o processo, como um todo, se dirige (seu objeto), coincidindo sempre com o objetivo que estimula o sujeito a executar esta atividade, isto é, o motivo" [14].

Os motivos podem exercer diferentes funções na estrutura da atividade; há motivos que cumprem a função de geradores de sentidos, que impulsionam a atividade, e há os motivos com a função de motivo-estímulo. No que diz respeito à relação entre motivos e atividade, Lagni [12] a descreve como "nexos ou ligações que se constroem na atividade do sujeito por suas mediatizações e que são relativadas por tais mediatizações. Essas relações se estabelecem tanto entre os motivos geradores de sentido e motivos-estímulo como entre motivo(s) e atividade(s)".

Para auxiliar no esclarecimento desse conceito, propõe-se o seguinte exemplo: um aluno, ao se envolver com um trabalho em grupo, participando e interagindo com os integrantes desse grupo, reconhece as vantagens desse tipo de trabalho e realiza-o buscando aprender com os colegas. Isto se caracteriza como um motivo especial, o qual estimula o sujeito.

No entanto, se em um trabalho desse tipo o aluno participa apenas por exigência do professor, havendo possibilidade, o faria sozinho. Esse caso não se configura como uma atividade segundo Leontiev, pois aquilo para o qual o trabalho em grupo se dirigia não coincide com o que induziu o aluno a fazer parte de um grupo. Assim, a atividade distingue-se da ação simples. Segundo Leontiev [14], "um ato ou ação é um processo cujo motivo não coincide com seu objetivo (isto é, com aquilo para o qual ele se dirige), mas reside na atividade da qual ele faz parte".

Ao resgatar o mesmo exemplo do trabalho em grupo, quando o aluno faz parte de um grupo apenas pela exigência do professor, isto se configura como uma ação, justamente porque o motivo não coincide com seu objetivo. Neste exemplo, o motivo seria a aprendizagem a partir da interação com outros alunos. No entanto, o objetivo do aluno é cumprir a exigência do professor. Além disso, "o objeto de uma ação é, por conseguinte, nada mais que seu alvo direto reconhecido" [14]. Neste exemplo, o objeto é a interação com os alunos, o que está de algum modo relacionado com o motivo da atividade. A partir do exposto, pode-se compreender que a ação "corresponde ao segundo nível da atividade, que, por sua vez, requer que motivos e objetos estejam estreitamente conectados a uma finalidade" [12].

O terceiro nível da atividade encontra-se nas operações que, segundo Lagni [12], se referem ao aspecto prático de sua respectiva realização. No que diz respeito às operações, Leontiev as entende como "o modo de execução de um ato. Uma operação é o conteúdo necessário de qualquer ação, mas não é idêntico a ela. Uma mesma ação pode ser efetuada por diferentes operações, e inversamente, numa mesma operação podem-se, às vezes, realizar diferentes ações. Isto ocorre porque uma operação depende das condições em que o alvo da ação é dado, enquanto uma ação é determinada pelo alvo" [14].

No caso do trabalho em grupo, o aluno pode interagir por meio de um diálogo, envio de e-mail, contato telefônico, os quais constituem operações diferenciadas que permitem a execução da mesma ação. Neste sentido, Engeströn [7] observa que as operações dependem das circunstâncias em que a ação é executada.

A partir da descrição e diferenciação entre ação, atividade e operação, é possível compreender que a TA proposta por Leontiev abrange três níveis: "no primeiro, temos a atividade ligada a um motivo. Mas a atividade só se realiza em termos de ações ligadas a um objetivo (...). Este é o segundo nível. Por fim, o terceiro nível trata de como levar a cabo a ação, ou seja, trata da operação e o meio de realizá-la" [12].

Estes níveis podem ser alterados, isto é, uma ação pode se transformar em operação, assim como um motivo pode exercer a função de gerador, e em outra atividade o mesmo motivo pode ter a função de estímulo complementar [12]. De acordo com Sforni [19], para que uma operação seja trazida à consciência, quando se está diante de uma situação-problema, "é fundamental que 
ela tenha se formado inicialmente como ação, processo em que cada movimento é consciente para o sujeito, e somente depois transformado em prática automatizada".

Lagni [12] descreve duas direções que podem contribuir com a alteração dos níveis: "a) uma atividade pode perder a sua motivação e tornar-se uma ação, e uma ação pode tornar-se uma operação quando a finalidade muda; b) a motivação de uma atividade pode se tornar o fim ou a finalidade de uma ação como resultado da transformação desta última em uma atividade mais integrada".

De modo geral, uma atividade é desencadeada pela motivação para a realização de um desejo do sujeito. Para realizar esta atividade são necessárias algumas ações conscientes, dirigidas para satisfazer o desejo. Quando uma atividade deixa de ser motivada intrinsecamente pelo desejo do sujeito ou surge outro desejo, esta pode tornar-se uma ação. Por fim, as ações ou objetivos conscientes vão determinar o conjunto de passos ou operações [4]. O que revela "a noção de que o ser humano orienta-se por objetivo/metas planejadas que lhe permitem satisfazer suas necessidades" [12].

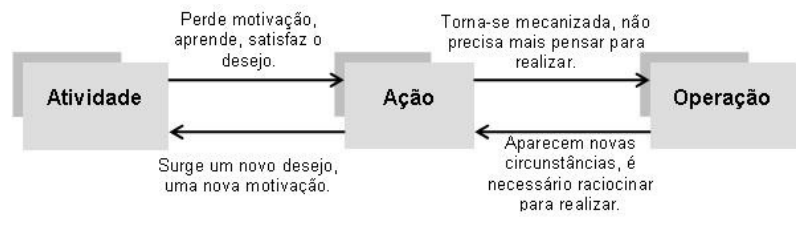

Figura 1. Níveis da teoria da atividade.

Desse modo, observamos que a atividade é um conceito complexo, pois para ser compreendida é necessário dar conta dos elementos que fazem parte e a influenciam. Segundo Gomes et al [7], "uma atividade é uma forma de agir de um sujeito, ou grupo de pessoas, direcionada a um objeto com o objetivo de alcançar um determinado resultado. $\mathrm{O}$ relacionamento recíproco entre o sujeito e o objeto da atividade é sempre mediado por uma ou mais ferramentas".

As atividades são realizadas como ações individuais e colaborativas, e as correntes e as redes de tais ações relacionam-se pelo mesmo objeto e motivo. Ao participar de uma atividade, executam-se as ações de modo consciente, que têm o objetivo imediato definido. As ações não podem ser compreendidas, entretanto, sem um quadro de referência criado pela atividade correspondente. Uma atividade pode ser realizada usando-se ações diferentes, dependendo da situação. Por outro lado, uma mesma ação pode fazer parte de diferentes atividades, sendo que os diferentes motivos da atividade farão com que cada ação tenha um sentido diferente no contexto de cada atividade [10].
Antes de uma ação ser realizada, de fato, ela é planejada mentalmente, utilizando modelos, o que pode ser denominado orientação. Nesta fase, há uma tentativa de descrever a execução dos passos da ação. No entanto, isto é sempre incompleto, como analisa Kuutti [10].

Engeström [7], acrescenta que a "atividade é coletiva, formada por um sistema complexo e mediatizado, é formada por ações e resulta em ações". A partir do referencial teórico proposto por Leontiev, Engeströn apresenta um modelo mais complexo de atividade humana, o qual é composto pelos seguintes elementos: "o objeto é considerado como centro da atividade, conectando as ações individuais à atividade coletiva; o sujeito refere-se ao indivíduo, ou subgrupo, a partir do qual é referenciado o ponto de vista da análise; a comunidade é compreendida como vários indivíduos e/ou subgrupos que compartilham o mesmo objeto; a divisão do trabalho referese à divisão horizontal de tarefas entre os membros de uma comunidade e à divisão vertical compreendida por relações de poder e status; as regras referem-se a regulamentos explícitos e implícitos, normas e convenções que norteiam as ações e interações em um sistema de atividade" [17].

O objeto como centro da atividade, analisa esse autor, é "algo dado e algo projetado ou antecipado (...) o objeto determina o horizonte de objetivos e de ações possíveis". A partir das conexões dos elementos descritos, o modelo é representado da seguinte maneira:

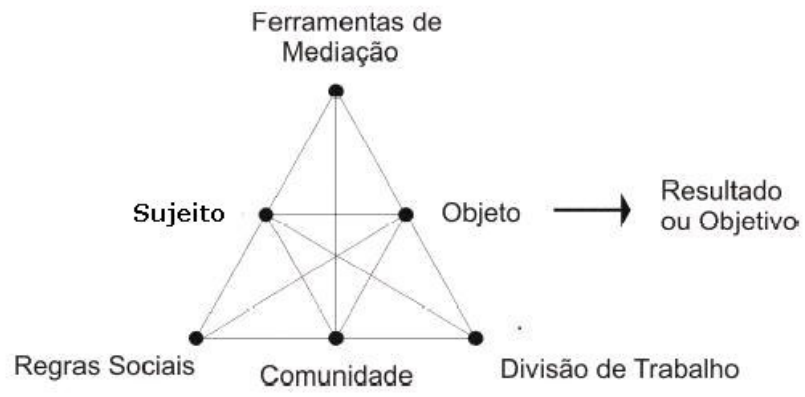

Figura 2. Representação do modelo da Teoria da Atividade. Fonte: Gomes et al [7].

\subsection{Princípios básicos da Teoria da Atividade}

Os princípios básicos da Teoria da Atividade, segundo Kaptelinn e Nardi [10], incluem a estrutura hierárquica da atividade, os objetos orientadores, a internalização/externalização e as ferramentas de mediação e desenvolvimento, e podem ser descritos da seguinte maneira: 
Princípio da unidade entre consciência e atividade: consciência e atividade são concebidas de forma integrada, isto é,

A consciência significa a mente humana como um todo, e a atividade a interação humana com sua realidade objetiva. Este princípio declara que a mente humana emerge e existe como um componente especial da interação humana com o seu ambiente. A mente é um órgão especial que aparece no processo de evolução para ajudar organismos a sobreviverem. Assim, ele pode ser analisado e entendido somente dentro do contexto da atividade humana [15].

Vygotsky [12] desenvolve sua teoria a partir da compreensão da indissolubilidade entre a consciência e a atividade. A consciência orienta a atividade e possibilita a execução do planejamento, estabelecimento de objetivos e ações para a sua realização.

- Princípio da orientação a objetos: a TA leva em conta o meio no qual os seres vivem. Kaptelinin e Nardi [10] referem-se a objetos orientadores, tendo em vista que os seres humanos vivem em uma realidade cultural e social que os influencia, isto é, "os seres humanos vivem num ambiente que é significativo para eles. Este ambiente consiste de entidades que combinam todos os tipos de características objetivas, incluindo aquelas determinadas culturalmente que por sua vez determinam as formas como as pessoas agem sobre essas entidades" [15].

Esse princípio também diz respeito ao planejamento das ações para o alcance dos objetivos definidos. Quanto mais bem planejada é uma ação, mais probabilidade há de ser bem sucedida. O planejamento deve levar em conta a realidade e as condições existentes para a sua realização.

- Princípio da estrutura hierárquica da atividade: na TA os procedimentos humanos são diferenciados em vários níveis: atividade, ação e operação, levando em conta os objetivos para os quais estes procedimentos são orientados. Para Martins e Daltrini [15], esta diferenciação "é de importância crítica para a diferenciação entre motivos, metas e condições, que estão associados à atividade, ação e operação, respectivamente".

Este princípio amplia a compreensão das diferenças humanas e leva em conta os sentimentos, expectativas e objetivos humanos que podem ser diferenciados. Assim, uma mesma atividade pode despertar diferentes motivos, ou seja, a atividade de um pode ser ação para outro.

- Princípio da internalização-externalização: refere-se aos mecanismos básicos dos processos mentais, sendo que estes são "derivados das ações externas através do curso da internalização. Internalização é o processo de absorção de informações (nas suas diversas formas) realizado pela mente humana, que ocorre a partir do contato com o ambiente em que a pessoa está inserida. A externalização é o processo inverso da internalização, manifestado através de atos, de tal forma que eles possam ser verificados e corrigidos, se necessário" [15].

Os proponentes da TA distinguem a atividade interna da externa. No entanto, colocam que ambas estão interrelacionadas, não sendo possível analisá-las independentemente [10].

A partir das internalizações e processamento de informações do mundo externo, o sujeito cria espaços e desenvolve processos psicológicos superiores, ao mesmo tempo em que externa o que foi processado internamente. Esse processo é resultado da concepção do ser humano como produto e produtor das relações sociais, o que implica dar uma grande importância à interação social.

- Princípio da mediação: a atividade humana é mediada por ferramentas e signos, ou seja, "as ferramentas são 'veículos' da experiência social e do conhecimento cultural" [15].

É importante destacar também a mediação de uma pessoa para outra, pois a atuação do outro cria condições e favorece o desenvolvimento humano. Lagni [12] destaca a importância dos instrumentos de mediação que orientam a ação sobre o mundo externo e dos instrumentos semióticos utilizados para orientar o mundo interno.

- Princípio do desenvolvimento: para conhecer um fenômeno é preciso entender seu desenvolvimento ao percorrer a sua história e as alterações que gera. Segundo Martins e Daltrini [15], "compreender estas alterações auxiliará no entendimento do seu estado atual". 


\subsection{A Teoria da Atividades e os processos de aprendizagem}

De acordo com a perspectiva histórico-cultural, a aprendizagem e o desenvolvimento são inerentes ao ser humano e são interdependentes, porém não se confundem. Na TA, este princípio diz respeito ao processo de motivação, ao desencadeamento de funções presentes na zona de desenvolvimento imediato e ao conhecimento dos fenômenos desde sua origem até o seu estado atual [12]. Podemos dizer, então, que na TA o desenvolvimento não é só o objeto de estudo, mas também um tipo de metodologia. O método de pesquisa baseia-se na participação e monitoração do desenvolvimento das pessoas envolvidas no estudo [10].

Esta teoria destaca a importância do social para o processo de aprendizagem, pois a mediação se dá a partir de ferramentas materiais e imateriais, e os processos intelectuais são originados no exterior por meio de experiências, interações e explorações do meio.

Ainda no que diz respeito à aprendizagem, as atividades com este propósito devem ser planejadas observando a realidade e as condições para a sua realização, na busca de estabelecer motivos que possam ser compartilhados pelo grupo para o qual se dirige. Esta ideia leva em conta a observação de Leontiev [12], de que o "homem se orienta por objetivos, agindo de forma intencional, por meio de ações planejadas".

A atividade, compreendida como um sistema integrado de orientação e processos psíquicos, inclui "a definição de metas, elaboração de um programa ou planejamento de ações adequadas ao objetivo e às condições para a sua realização, até atingir seus resultados finais" [12].

A partir disso é possível enfatizar a importância de um planejamento educacional que considere as condições, os recursos e a realidade escolar. Da mesma forma como a atividade proposta durante a pesquisa empírica necessitou da seleção de recursos e o estabelecimento de metas e regras para a sua execução, na procura de sintonizar a realidade dos alunos, as atividades escolares precisam levar em conta o princípio de orientação ao objeto, da mediação e a importância do social para a aprendizagem.

No que se refere às ferramentas mediadoras, destacam-se o computador e as suas possibilidades para o contato com informações e com outras pessoas. Assim, no próximo item abordamos o uso do computador e as considerações da TA sobre o uso desta ferramenta.

\subsection{Teoria da atividade: um olhar sobre o uso da tecnologia e sobre a colaboração}

A TA baseia-se em princípios, dentre os quais se destaca a mediação e a orientação a objetos. Neste trabalho, ao focar-se a atividade mediada por tecnologias digitais, resgata-se a atividade proposta por Kaptelinin e Nardi [10] utilizando um checklist. Esta atividade foi organizada em cinco fases, com base na TA, para identificar os fatores mais importantes que influenciam o uso da tecnologia. As fases da atividade podem ser adaptadas para outras atividades que utilizem tecnologias para o seu desenvolvimento. As fases da atividade são descritas a seguir:

Na primeira fase são fornecidas aos participantes informações, orientações ou dados, visando permitir a análise e a indicação de problemas potenciais presentes ou propostos pela atividade e possibilitar o apontamento de possíveis soluções.

$\mathrm{Na}$ segunda fase o checklist é introduzido. Ele é composto por quatro perspectivas para avaliar o uso da tecnologia. São elas:

a) estrutura da atividade do usuário: como a tecnologia facilita e permite alcançar os objetivos;

b) estrutura do ambiente: observar como ocorre a integração das ferramentas, recursos, objetivos e normas sociais;

c) estrutura e dinâmica da interação: observar a interação dos componentes internos e externos da atividade, bem como suas transformações a partir do suporte ao uso da tecnologia;

d) desenvolvimento: observar o desenvolvimento dos componentes descritos acima durante a atividade.

$\mathrm{Na}$ terceira fase explicita-se aos participantes do grupo como usar o checklist. Duas questões são discutidas:

a) ajustamento do checklist às finalidades específicas da análise em questão;

b) seleção de uma metodologia apropriada para conduzir a pesquisa empírica.

$\mathrm{Na}$ fase seguinte, os participantes aplicam o checklist à atividade para interpretar e analisar os dados, trabalhando individualmente ou em grupos pequenos.

A fase final do exercício é a discussão do grupo sobre a atividade realizada [10]. 
O checklist contempla a maioria dos fatores presentes na interação homem-computador, levando em conta o contexto no qual ocorre. Assim, pode ser utilizado para orientar pesquisas e atividades nessa área, com a intenção de compreender o seu contexto e o modo como a ferramenta é usada.

Além disso, a partir das ideias desenvolvidas pelos autores citados, destaca-se a utilização de desafios e a busca de soluções como propulsores para o estabelecimento da aprendizagem colaborativa, tendo em vista que o centro da atividade passa a ser a proposta de soluções que, no ambiente coletivo, pode ganhar maior qualidade. Segundo Sforni [19], "a mobilização (...) para a aprendizagem é resultado de um 'desejo de pertencer' à coletividade. Nesse sentido, as atividades realizadas no ambiente sociocultural são mobilizadoras da aprendizagem". Assim, destacamos a proposta de desafios em um contexto coletivo como estratégia mobilizadora para a aprendizagem.

\section{Metodologia da pesquisa}

A pesquisa realizada caracteriza-se como sendo qualitativa, pois concebe a realidade como a relação dinâmica entre o sujeito e o mundo. Esta foi realizada em uma escola pública estadual, localizada na cidade de Florianópolis, no estado de Santa Catarina, Brasil.

Os sujeitos da pesquisa foram os alunos de duas turmas de oitava série do Ensino Fundamental dessa escola, uma matutina e outra vespertina e os professores que trabalham nessa escola. Nesse sentido, a pesquisa envolveu duas estratégias: na primeira, o trabalho com os alunos, foi proposta uma atividade colaborativa para ser desenvolvida na disciplina de História tendo como conteúdo as duas grandes guerras mundiais. A pesquisa realizou-se na sala informatizada da escola com a participação direta do pesquisador no desenvolvimento das atividades e dos professores da disciplina de História e um total de 43 alunos, 18 de uma turma e 23 de outra. Foi aplicado aos alunos um questionário antes do início da atividade colaborativa proposta, procurando estabelecer seu grau de conhecimento e utilização dos equipamentos computacionais, bem como conhecer os tipos de trabalhos realizados em sala de aula. Ao final da atividade de pesquisa outro questionário foi aplicado com o objetivo de proporcionar um espaço de avaliação do trabalho desenvolvido pelos grupos. Além disso, foram realizadas entrevistas com $20 \%$ dos alunos, para aprofundar os dados fornecidos pelo questionário.

O trabalho realizado com os alunos de oitava série foi desenvolvido com base na proposta pedagógica
WebQuest e na Metodologia da Problematização, visando trabalhar o conteúdo de modo colaborativo. Estas duas referências configuram-se como uma boa alternativa metodológica, pois suas características propiciam e incentivam o trabalho em grupo, tendo em vista o foco na solução de problemas.

A metodologia WebQuest foi desenvolvida pelo professor Bernie Dodge, da San Diego State University, em 1995, para orientar atividades de pesquisa que utilizam a Internet. À proposta de seu autor é que seja um modelo para dimensionar o uso educativo da Web e favorecer a aprendizagem colaborativa e os processos investigativos na construção do saber. Em linhas gerais, para compor uma WebQuest é sugerido que tenha uma introdução, a tarefa, o processo de realização, os recursos, as orientações, a avaliação e as conclusões resultantes do trabalho realizado Dodge [6].

Outra referência utilizada foi a Metodologia da Problematização, descrita por Berbel [1], a qual completa e fundamenta a elaboração de atividades utilizando a Internet. Para essa autora, a metodologia da problematização pode ser compreendida a partir do Arco de Maguerez. Este arco tem como ponto de partida a realidade, ou seja, começa pelos acontecimentos da vida real e após passar pela reflexão retorna para a vida real. Assim, para o desenvolvimento de um trabalho com base nesta metodologia é preciso levar os alunos a observar a realidade, para que seja identificado o que se mostra dissonante, necessário e/ou preocupante. Daí, então, extrair os elementos dessa realidade, problematizá-los e, posteriormente, identificar o que pode ser trabalhado e corrigido. Esta metodologia requer dos seus participantes tanto um trabalho de reflexão quanto uma visão analítica e crítica da realidade.

Neste sentido, a atividade colaborativa proposta para os alunos envolvia um contexto no qual era possível relacionar aspectos da realidade e dar sentido à atividade. Este entrelaçamento com a realidade visou mobilizar reflexões e o envolvimento do aluno para a busca de informações e a interação com os colegas da equipe.

Os desafios aos alunos, os quais estavam contidos numa atividade estruturada a partir dessas duas referências metodológicas, foi apresentada no formato HTML, publicada no Ambiente Virtual de Aprendizagem (AVA) e estruturada da seguinte maneira:

a) Apresentação: introduzia o aluno na atividade ao apresentar os procedimentos iniciais para navegar no conteúdo disponibilizado no AVA. 
b) Contexto: apresentava o contexto criado para a atividade e convidava os alunos a integrarem-se em um comitê que iria julgar os países que participaram da Primeira e da Segunda Guerra Mundial. Para participar desse comitê, o aluno precisava realizar uma investigação em grupo, o que deveria resultar em um relatório a ser disponibilizado no ambiente.

c) Desafios: apresentava os desafios representados por questões orientadoras para a investigação. A partir dos quais os grupos deveriam escolher dois, dos cinco desafios propostos.

d) Recursos: indicava sites pré-selecionados para a realização da pesquisa que respondesse aos desafios escolhidos. Cada indicação era acompanhada por uma breve descrição do seu conteúdo.

e) Avaliação: descrevia o que é esperado de cada grupo no relatório final, bem como orientava sobre a participação de cada aluno no grupo.

f) Créditos: apresentava as pessoas envolvidas no desenvolvimento da atividade.

Esta atividade foi realizada a partir da utilização das ferramentas de comunicação, dos espaços colaborativos e de pesquisa disponíveis em um ambiente virtual de aprendizagem. A utilização deste suporte foi fundamental, pois os grupos eram formados por quatro alunos, dois da turma matutina e dois da vespertina, sem haver o encontro presencial.

A utilização desta tecnologia permitiu ampliar o espaço geográfico e temporal da sala de aula ao viabilizar o trabalho conjunto entre duas turmas de horários escolares distintos.

\section{Resultados e discussão}

A TA oferece subsídios para compreender o contexto e o funcionamento do trabalho colaborativo e a possibilidade de analisar este tipo de atividade a partir dos elementos descritos por esta teoria, tais como o objeto, o sujeito, a comunidade, a divisão de trabalho e as regras. A seguir, baseando-se na figura utilizada por Kuuiti [10] apresenta-se os elementos de análise da atividade realizada na escola, com alunos de oitava séries do Ensino
Fundamental.

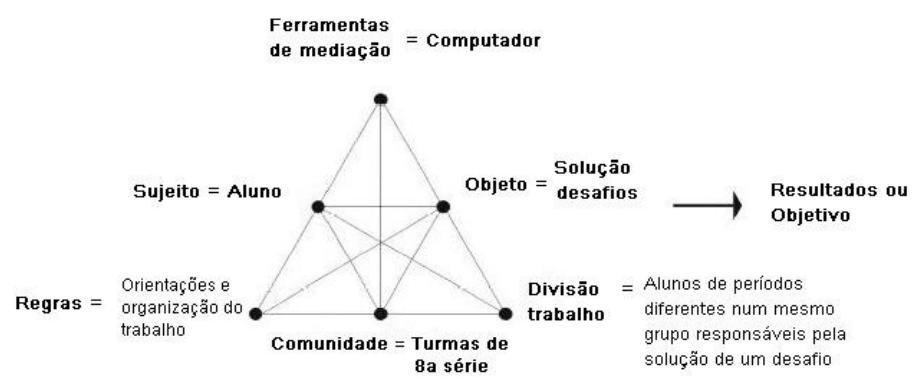

Figura 3- Análise da atividade desenvolvida na escola a partir do modelo proposto pela Teoria da Atividade.

Fonte. Adaptação a partir do modelo apresentado por Kuuiti [10]

A partir deste modelo é possível descrever os elementos do seguinte modo:

a) Ferramentas de mediação: computador ligado à rede e materiais didáticos utilizados para pesquisa e solução dos desafios.

b) Objeto: busca de soluções aos desafios propostos, o que resultou na construção coletiva de um trabalho postado na ferramenta "Ambiente de Grupo", do ambiente virtual de aprendizagem.

c) Sujeito: os alunos e grupos de trabalho de duas turmas de $8^{\mathrm{a}}$ série do EF, matutina e vespertina.

d) Comunidade: as turmas de $8^{\mathrm{a}}$ série, matutina e vespertina, da escola na qual a pesquisa foi realizada.

e) Divisão do trabalho: estratégia utilizada para a solução dos desafios pelos grupos, no que se refere à divisão horizontal. Em geral, os alunos de um período dedicaram-se à solução de um dos desafios e os alunos do outro período, que compunham um grupo, dedicaram-se a outro. No que se refere à divisão vertical, o professor está na ponta da hierarquia, pois foi quem definiu o formato do trabalho, o seu conteúdo e as regras. Em alguns grupos surgiu a figura do líder, para organizar e delegar responsabilidades.

f) Regras: orientações para o desenvolvimento do trabalho, como a formação dos grupos 
com quatro ou cinco alunos, sendo que dois ou três deles deveriam ser de turmas diferentes; escolha de dois desafios entre os cinco propostos; a definição da data de entrega do trabalho final, a utilização do computador para o desenvolvimento do trabalho, entre outras.

A partir da atividade desenvolvida foi possível evidenciar que o computador ligado a rede configurou-se como uma importante ferramenta de mediação, pois possibilitou ampliar o espaço de sala de aula e os sujeitos envolvidos na atividade, ao incluir alunos de turnos distintos que solucionam desafios colaborativamente sem encontrarem-se presencialmente. Desse modo, esse potencial amploou as possibilidades de interação e aprendizagem.

\subsection{Estratégias utilizadas para o desenvolvimento do trabalho colaborativo}

A colaboração possui níveis, segundo Campos et al [3]. Na atividade proposta foi possível observar o primeiro nível descrito, ou seja, a divisão de trabalho, na qual cada integrante do grupo fica responsável por uma tarefa. Este era o procedimento utilizado pela maioria dos grupos. Segundo o A. 1, o trabalho foi dividido entre todos do grupo; e para o A. 4, nós combinamos fazer o 2 e o 5 a equipe ficou com o 5 e nos ficamos com o desafio 2. Esta estratégia é descrita na TA, segundo Lagni [12], como a divisão horizontal de tarefas entre os membros da comunidade e a divisão vertical de poderes.

Apesar da prevalência desse modo de colaboração, alguns grupos alcançaram o estado de colaboração no qual há momentos de trabalho individual e momentos de trabalho em grupo [2]. Os momentos de trabalho em grupo ocorriam virtualmente de modo assíncrono, pois o grupo só podia encontrar-se interagindo por meio da ferramenta de comunicação, em tempos diferentes. Segundo A. L, todo mundo ajudou bastante, a outra turma ficou com o desafio 1 e nós com o 2, mas eles nos ajudaram e vice-versa. $\mathrm{O}$ estado de colaboração foi mais visível no momento da escolha dos desafios, pois era necessário negociar com os integrantes, e na finalização do trabalho a ser entregue.

Isso demonstra a necessidade de se lidar melhor com a atividade colaborativa, pois é necessária a construção conjunta das propostas e das condições para o desenvolvimento do trabalho em grupo, como o espaço, o tempo e o assunto. Além disso, podemos ter alunos que não sabem, por falta de orientação ou experiência, ou não desejam trabalhar em equipe.

Diante disto, torna-se necessário utilizar estratégias motivadoras para incentivar o trabalho colaborativo e oferecer facilidades para este tipo de aluno ou, ainda, pensar em atividades flexíveis, nas quais seja possível também o trabalho individual.

De modo geral, os alunos negociaram a escolha dos dois desafios dentre os cinco apresentados, sendo que o trabalho foi dividido em duas partes; uma parte ficou sob a responsabilidade dos alunos de um turno, e outra com os alunos do outro turno, apesar de todos fazerem parte do mesmo grupo. Assim, dois ou três alunos trabalharam um desafio presencialmente, utilizando o mesmo computador para o seu desenvolvimento.

Nesse sentido, foi identificada a divisão do trabalho realizada pelos alunos, opção sintetizada na seguinte fala de um deles: utilizamos a divisão de tarefas como uma estratégia para o desenvolvimento do trabalho em grupo, para que cada um ficasse com uma parte, para tornar o processo mais rápido.

Nesse contexto encontramos níveis mais avançados de colaboração, a exemplo da colaboração como meio. Segundo Brna [2], a colaboração como meio tem o objetivo de promover a aprendizagem a partir de ações colaborativas. Esta estratégia foi favorecida pelas facilidades encontradas pelos alunos, como o encontro presencial e a restrição do meio com relação ao número insuficiente de computadores, o que tornava necessário o compartilhamento desse equipamento. No entanto, em algumas dessas duplas ou trios foi mantida a divisão de trabalho como estratégia para o desenvolvimento da atividade.

Quanto mais elevado é nível de colaboração atingido pelo grupo, mais a atividade se diferencia de uma simples ação, pois os membros do grupo são movidos por desejos e necessidades em comuns e compartilhadas. Isso porque na atividade o processo para o qual se dirige coincide com os objetivos que estimulam o sujeito a executar a atividade.

De outra maneira, ao identificarmos diferentes níveis de colaboração dentro de um mesmo contexto escolar, reforça-se a ideia de que uma mesma atividade pode despertar diferentes motivos. Havia alunos que tinham como objetivo de cumprir a tarefa ou queriam ter nota para passar de ano, outro motivados com a atividade queriam resolver os desafios e aprender com os colegas para propor a melhor solução. 
No que se refere ao contexto, o princípio de orientação ao objeto considera a realidade cultural e social, que no caso de nossa pesquisa se traduz na escola em que a mesma foi desenvolvida, uma escola pública que atende um grupo heterogêneo com experiências e história de vida distintas. Assim, cada um influenciado por sua realidade cultural e social vai lidar com a atividade proposta de forma diferenciada, pois essa realidade influencia a forma como as pessoas agem. Por isso, discutir a atividade colaborativa é tarefa complexa que envolve multivariáveis.

A partir da análise realizada sobre o modo como a colaboração ocorreu e as estratégias utilizadas pelos alunos para realizar a atividade, bem como com a descrição da proposta da atividade é possível utilizar o checklist, com base na TA, desenvolvido por Kaptelinin e Nardi [10]. A esse respeito, propõe-se a identificação das fases descritas na atividade proposta focando a mediação e a colaboração realizada por meio do uso da Internet na situação específica pesquisada.

\section{Fase 1}

Descrição: Foram fornecidos informações, orientações ou dados, para a análise e identificação de problemas.

Identificação na Atividade: Estas informações e orientações foram fornecidas por meio da WebQuest disponibilizada. As orientações concentram-se principalmente na Apresentação, no Contexto e na Avaliação, enquanto as informações concentramse, principalmente, no item Recursos.

\section{Fase 2}

Descrição: Verificação da atividade a partir de quatro perspectivas:

(i) Estrutura da atividade do usuário: como a tecnologia facilitou e permitiu alcançar os objetivos.

(ii) Estrutura do ambiente: como se deu a integração das ferramentas, recursos, objetivos e normas sociais.

(iii) Estrutura e dinâmica da interação: como ocorreu a interação dos componentes internos e externos da atividade, a partir do uso de suportes tecnológicos.

Desenvolvimento: evolução da atividade a partir dos componentes descritos.

Identificação na Atividade: A tecnologia possibilitou realizar pesquisas e coletar informações, interagir com o grupo, fazer os registros do trabalho e publicá-los.

O objetivo do trabalho era promover o trabalho colaborativo para a solução de problemas propostos, no formato de desafios. Neste sentido, os recursos possibilitaram a interação e viabilizaram a realização com outra turma, o que possibilitou ultrapassar as barreiras físicas da sala de aula. Além disso, para a realização foram estipuladas regras para possibilitar o alcance deste objetivo e potencializar o uso dos recursos, como a formação de grupos com alunos de turmas diferentes, utilização do Web Ensino e entrega do trabalho na versão digital.

Foi possível observar duas formas de interação, uma que ocorria presencialmente entre os alunos da mesma turma que utilizavam o mesmo computador, e outra com os alunos da outra turma, todos fazendo parte do mesmo grupo. No primeiro modo a interação foi mais intensa, buscando a solução de problemas de maneira conjunta, tanto relacionados aos desafios, como ao manuseio dos recursos tecnológicos. No segundo, a interação foi menos intensa e centrou-se na organização do trabalho e na divisão das tarefas.

O desenvolvimento da atividade de pesquisa proposta observou os componentes descritos (alunos e professores), levando em conta os procedimentos da atividade e os da utilização do ambiente Web Ensino.

\section{Fase 3}

Descrição: Explica-se aos participantes como usar a lista de verificação.

Identificação na Atividade: Foram explicados os objetivos e contexto da atividade e fornecidas informações sobre o que deveria ser feito, os processos envolvidos, a avaliação e os recursos disponíveis.

\section{Fase 4}

Descrição: Aplica-se a lista de verificação à atividade, para interpretar e analisar os dados, trabalhando individualmente ou em grupos pequenos.

Identificação na Atividade: Os alunos utilizaram as orientações e informações postas à disposição no ambiente de aprendizagem (na WebQuest) para desenvolver o trabalho em pequenos grupos.

\section{Fase 5}

Descrição: Discussão do grupo sobre a atividade.

Identificação na Atividade: A discussão entre os integrantes dos grupos ocorreu durante todo o processo, principalmente na escolha de quais desafios seriam solucionados. Além disso, a atividade foi avaliada pelos alunos, a partir de colocações orais na turma e por meio do questionário de avaliação da atividade, aplicado no final.

Tabela 1. Identificação do checklist da teoria da atividade.

\section{CONSIDERAÇÕES FINAIS}

As atividades colaborativas reestruturam as relações sociais e os papéis dos sujeitos no processo educativo, pois os alunos passam a serem responsáveis pela organização do trabalho, buscam fontes alternativas de pesquisas e têm o foco nas contribuições dos integrantes 
do grupo. O professor, por sua vez, passa a ser fundamental no planejamento da atividade e na concepção da proposta, pois durante o desenvolvimento da atividade orienta os alunos e os auxilia na resolução de suas dúvidas. Contudo, cabe ao grupo definir a sua trajetória.

Pode-se inferir que a colaboração não se restringe à possibilidade de construir conhecimentos coletivos, mas ao exercício de habilidades e comportamentos sociais que aprimoram a formação do sujeito. Quando ocorre a divisão horizontal do trabalho, a divisão de tarefas, e a divisão vertical, papéis organizados de maneira hierárquica, os alunos com dificuldades acabam ficando no nível mais baixo da hierarquia do grupo e recebem tarefas simples, que pouco contribuem para a superação de suas dificuldades.

Destacam-se estes aspectos tendo em vista a identificação da divisão de trabalho na realização de atividade colaborativa, o que remete não só à divisão de tarefas no grupo como ao estabelecimento de relações de poder dentro dele, bem como o distanciamento da perspectiva da atividade e aproximação com a ação, em que o motivo que move o sujeito a atuar diferencia-se do objetivo para o qual o processo se dirige.

Desse modo, as possibilidades oferecidas por atividades que proporcionem espaços de colaboração sofrem um forte revés, devido a esta forma de organização do trabalho em grupo, que não propicia compartilhamento de metas e concepções, ainda que os alunos tenham apresentado argumentos em defesa dela.

Apesar da utilização da divisão de trabalho, ocorreram iniciativas de compartilhamento e interação, principalmente no espaço de sala de aula reservado para o desenvolvimento do trabalho, buscando a construção de soluções mais adequadas e eficientes. Além disso, esta estratégia inseriu elementos diferenciados nas atividades de sala de aula, instigou e desafio os alunos para a superação, e o grupo configurou-se como uma possibilidade para sua efetivação.

\section{Referências}

[1] Berbel, Neusi A. N. (Org.) Metodologia da problematização: fundamentos e aplicações. Londrina: Editora da UEL, 1999.

[2] Brna, Paul. Modelos de colaboração. Revista Brasileira de Informática na Educação. Florianópolis, n. 3., pg. 9 - 15, setembro, 1998.
[3] Campos, Fernanda C. A.; Santoro, Flávia M.; Borges, Marcos R. S.; Santos, Neide. Cooperação e aprendizagem on-line. Rio de Janeiro: DP\&A, 2003.

[4] Cruz, Cristiano C. Análise da educação e da informática na sociedade segundo a Teoria da Atividade. In XXI Congresso da Sociedade Brasileira de Computação. Fortaleza, 2001. Anais XXI Congresso da Sociedade Brasileira de Computação. Fortaleza: SBC, 2001. http://www.dspcom.fee.unicamp.br/cristia/artigo s/SBC2001/artigo_sbc.pdf., Jan. 2005.

[5] Dillenbourg, P., Baker, M., Blaye, A. \& O'Malley, C. The evolution of research on collaborative learning. In SPada, E. Reiman, P. Learning in Humans and Machine: Towards an interdisciplinary learning science. Oxford: Elsevier,1996 (p. 189-211).

[6] Dodge, B. WebQuests: A Technique for Internet - Based Learning. The Distance Educator, v.1, n 2, 1995.

[7] Engeström, Yrjö. Cultural-Historical Activity Theory. In Center for activity Theory and developmental work research. http://www.edu.helsinki.fi/activity/pages/chatan ddwr/activitysystem/, Jun. 2007.

[8] Gomes Neto, Genésio; Gomes, Alex Sandro; Tedesco, Patrícia Azevedo. Aliando Teoria da Atividade e TROPOS na elicitação de requisitos de ambientes colaborativos de aprendizagem. In: Workshop em Engenharia de Requisitos WER03, Piracicaba (SP), 2003. Anais do Workshop em Engenharia de Requisitos WER03. Piracicaba (SP): 2003. http://www.cin.ufpe.br/ asg/producao/Genesio WerLNCS.pdf, Jul. 2007.

[9] Kaptelinin, Victor. Computer-mediated activity. In: Nardi, Bonnie A. (Org.). Context and consciousness: activity theory and humancomputer interaction. Cambridge: MIT, 1996.

[10] Kaptelinin, Victor. Nardi, Bonnie A. Activity Theory: Basic Concepts and Applications. In Conference on Human Factors in Computing Systems. Georgia (US): CHI97, 1997. http://www.acm.org/sigchi/chi97/proceedings/tu torial/bn.htm, Mai. 2006.

[11] Kuutti, Kari. A framework for HCI research. In: Nardi, Bonnie A. (Org.). Context and consciousness: activity theory and human- 
computer interaction. Cambridge : MIT, 1996.

[12] Lagni, Delia Terezinha. Teoria da atividade e a psicologia histórico-cultural: um estudo a partir da Proposta Curricular de Santa Catarina. 2004. Dissertação (Mestrado em Educação) - UFSC, Florianópolis, 2004.

[13] Lampreia, Carolina. Linguagem e atividade no desenvolvimento cognitivo: algumas reflexões sobre as contribuições de Vygotsky e Leontiev. Psicologia: Reflexão e Crítica. [online]. V.12, no.1 p.225-240. 1999. http://www.scielo.br/scielo.php?script=sci_artte xt\&pid=S0102-

79722099000100015\&lng=es\&nrm=iso, Ago. 2004.

[14] Leontiev, Aléxis N. Uma contribuição à teoria do desenvolvimento da psique infantil. In: Vigotsky, L. S; Luria, A. R; Leontiev, Aleksei N. et al. Linguagem, desenvolvimento e aprendizagem. São Paulo: Ícone - EDUSP, 1998.

[15] Martins, Luiz Eduardo G. Daltrini, Beatriz Mascia. Utilização dos preceitos da teoria da atividade na elicitação dos requisitos do software. In XIII Simpósio Brasileiro de Engenharia de Software. Florianópolis, UFSC: 1999. http://www.inf.ufsc.br/sbes99/anais/SBESCompleto/06.pdf, Jun. 2004.

[16] MendeS, J. R. Possibilidade e limites da informática na educação: uma abordagem a partir da Teoria da Atividade. 2002. Dissertação (Mestrado em Tecnologia). CEFETPR, Curitiba, 2002.

[17] Menezes, G. G. O paradigma CSCL e a avaliação discente mediada pelas NTICs: reflexões através de contradições da Teoria da Atividade. 2002. Dissertação (Mestrado em Tecnologia). CEFETPR, Curitiba, 2002.

[18] Nardi, Bonnie A. (Org.) Context and consciousness: activity theory and humancomputer interaction. Cambridge: MIT, 1996.

[19] Sforni, Marta Sueli de F. Aprendizagem conceitual e organização do ensino: contribuições da Teoria da Atividade. Araraquara: JM Editora, 2004.

[20] Willis, Neil. Uden, Lorna. Designing user interfaces using activity theory. In: 34th Internacional Conference on System Sciences. 2001.

Hawaii. http://csdl.computer.org/comp/proceedings/hicss /2001/0981/05/09815031.pdf, Out. 2004. 